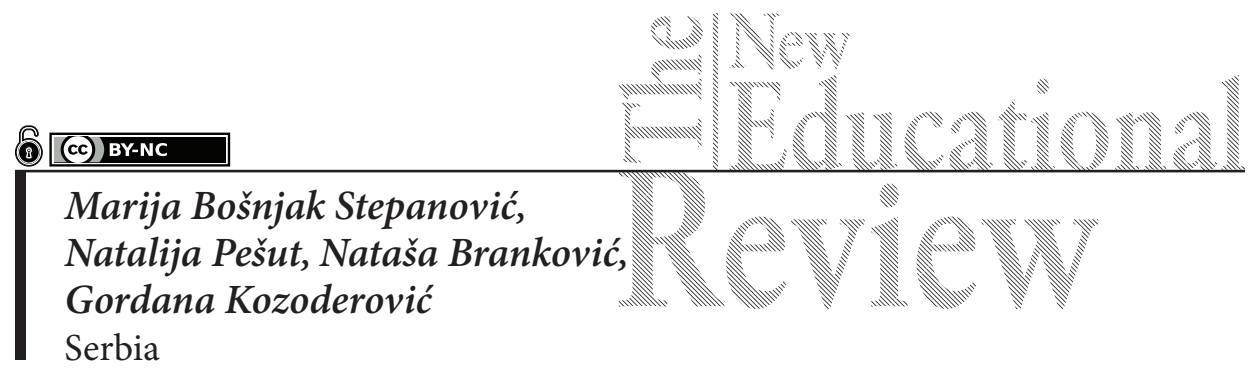

\title{
Primary School Students' Misconceptions about Physical Properties of Water
}

DOI: 10.15804/tner.2019.57.3.10

\begin{abstract}
Misconceptions are widely present among the students of all ages. The aim of this investigation was to determine the presence of misconceptions in understanding physical properties of water and to identify the most common ones. Quantitative analysis of data from the diagnostic conceptual test was performed on a sample of 243 first and third grade students from three elementary schools in Sombor, Serbia. It was shown that the impact of gender and school affiliation were not proven to be statistically significant factors in test achievements, while the children's age significantly affects test results, as expected. Synthetic and scientifically correct answers were more frequent among the third grade students, while spontaneous answers were more common among the first graders. Nevertheless, a significant proportion of spontaneous answers implies that misconceptions about physical properties of water are almost identical and deep-rooted among students of both ages. Identifying children's misconceptions provides a basis for development of accurate conceptual understanding.
\end{abstract}

Key words: primary teaching, science, misconceptions, physical properties of water

\section{Introduction}

The main goal of education is to enable children for further schooling, lifelong learning and better functioning in everyday life. In science education, students should be able to develop the skills, the will, the flexibility in thinking, key concepts 
and understanding of how science ideas and knowledge are obtained (Harlen, 2013). In 2009 approximately $34 \%$ of students in Serbia failed to demonstrate a satisfactory level of scientific literacy in PISA tests, meaning that these students have insufficient scientific knowledge and that it can be applied to a limited number of typical situations (Pavlović-Babić \& Baucal, 2010).

The term "misconception" refers to the situation in which the student's idea or understanding of a phenomenon differs from the scientific concept. They can occur as children's incorrect, intuitive answers, but also, even after formal teaching, they still misunderstand a scientific concept and therefore explain it erroneously (Kubiatko \& Prokop, 2009). Therefore teachers should understand both the students' conceptions and misconceptions, in order to correct, or initiate the process of conceptual change towards appropriate scientific concepts (Allen, 2010).

The reconstruction of the existing knowledge in teaching can be achieved by creating situations in which the student becomes unsatisfied with their own (spontaneous) notions. The new (scientific) concepts are understandable and credible, and the conceptual change is a gradual and evolutionary rather than sudden and revolutionary process (Taylor \& Kowalski, 2004).

\section{Research Problem}

Formulation of scientific concepts in teaching must upgrade the ideas developed by a child through their personal experience. Traditional teaching is mainly oriented towards passive adoption and reproduction of the subject content, missing the confirmation of substantial understanding. Consequently, sporadic facts are often adopted, lacking a concept as a indispensable requirement to create functional knowledge. In the past two decades, research has been dedicated to the investigation of students' misconceptions, as well as to the study of the effects that teaching methods exert on scientific concept development by a conceptual change (Pine, Messer \& St. John, 2001; Kikas, 2005; Yin, Tomita \& Shavelson, 2008; Smolleck \& Hershberger, 2011).

\section{Research Focus}

The aim of this research was to determine the presence and frequency of misconceptions in understanding physical properties of water, and to identify the most common misconceptions. The obtained information can be used to encourage elementary school teachers to continuously and consistently identify and correct children's misconceptions.

It was established that most children could successfully distinguish solid and liquid states, but not gas and liquid states (Smolleck and Hershberger, 2011). It 
was found that children mix up steam, gas, mist and smoke, as well as melting, dissolving and disintegrating, and that the factors influencing these processes are unclear to them (Pine, Messer \& St. John, 2001). Many primary students are not able to coherently adopt the concept of horizontality of the free liquid surface, having difficulty with conservation of the volume (Bošnjak Stepanović \& Gorjanac Ranitović, 2016). The ability to understand the concept of water cycle in nature was investigated by Kikas (2005). A vast array of answers were obtained, from anthropocentric ones (because humans and plants need it), to synthetic answers with scientifically incomplete assertions about evaporation of water, forming clouds and precipitations. Yin, Tomita \& Shavelson (2008) investigated misconceptions about the phenomenon of floating and sinking.

\section{Methodology of Research}

\section{General Background of Research}

This study investigated the children's understanding and explanation of scientific facts covered by the subject contents about water. Topics about water are dominant in the first and third grade of primary school curricula, thereby the first and third-graders were elected as a sample group for this investigation.

\section{Sample of Research}

The sample was selected from a population of first-graders (six - seven years of age) and third-graders (eight - nine years of age). In total, 243 children (111 girls and 132 boys) from three elementary schools in Sombor, Serbia were included in the research conducted in spring 2016/17.

\section{Instrument and Procedures}

A diagnostic conceptual test was constructed based on the subject contents about water in the first and third grade of national curricula for the elementary school. The test covered contents about basic properties of water (shape, volume, free surface), states of water and the water cycle in nature, objects in water (floating and sinking) and solubility in water.

Metric characteristics of the test were verified in a pilot study involving 55 first- and third-graders from two elementary schools in Sombor. The test was created in concordance with the results of relevant studies concerning students' misconceptions about physical properties of water (Pine, Messer \& St. John, 2001; Kikas, 2005; Yin, Tomita \& Shavelson, 2008; Smolleck \& Hershberger, 2011). Every 
correct answer was scored by one point. The open-ended questions in which the explanations of natural phenomena and processes were required were scored as follows: scientific explanations were assigned two points and synthetic answers were scored by one point. Naive (spontaneous) - incorrect explanations did not get any points, but they were classified according to their similarities, enabling the formation of the list of characteristic misconceptions for each specific physical property of water. The Cronbach Alpha value was used for estimation of the scale reliability, and it was 0.631 for our test, which is considered acceptable for knowledge tests in early school age (Pallant, 2010). Testing was conducted within one school class (45 minutes).

\section{Data Analysis}

Descriptive statistical measures (frequencies and percentages) were used for quantitative data analysis of the diagnostic test, in order to obtain the distribution of test results by score intervals in the entire sample and within subpopulations: gender, age and school. The Mann-Whitney test (for gender and age) and Kruskal-Wallis test (for school) were used to estimate the variations between subpopulations in test scores. The following qualitative criteria were used to classify answers into four groups (Petrović, 2006):

- Spontaneous answers are everyday answers, based on practical and sensory-perceptive experiences which are characterized by the absence of influence of teaching and scientific facts.

- Synthetic answers include certain features of both, spontaneous as well as scientific answers: they are based on experience with the existence of scientific thinking, but expressed in awkward linguistic constructions, answers learned by heart and associatively (often incorrectly) connected information.

- "I don't know" answers are the ones where a student is not able to explain the notion, or is not familiar with particular facts and concepts.

- Scientific answers are considered to be the consequence of the concept adopted by the student. These answers represent the effect of teaching and the knowledge acquired at school.

Descriptive statistical measures (frequencies and percentages) were also used in qualitative analysis of children's answers, and the results were grouped according to subject contents (questions) and groups of answers (spontaneous, synthetic, "I don't know" and scientific) in each grade (first and third). Qualitative analysis included the analysis of some authentic examples of students' answers. 


\section{Results of Research}

Distribution of test results by score intervals in the entire sample and within subpopulations

The test achievements are presented as a scale which measures score intervals defined by the number of points and percentages.

Distribution of test achievements by score intervals in the entire sample and within subpopulations gender, age and school is shown in table 1 , where $\mathrm{f}$ represents the number of students with a score in each interval, and $\mathrm{p}$ is the percentage of students relative to the total number of students or to the number of students within the subpopulation.

Table 1. Distribution of test achievements by score intervals in the entire sample and within subpopulations gender, age and school

\begin{tabular}{|c|c|c|c|c|c|c|c|c|c|c|c|c|}
\hline \multirow[t]{2}{*}{ sample } & \multicolumn{2}{|c|}{ subpopulation } & \multicolumn{2}{|c|}{$\begin{array}{c}\text { I } \\
0-8 \text { points } \\
(0-20 \%)\end{array}$} & \multicolumn{2}{|c|}{$\begin{array}{c}\text { II } \\
9-17 \text { points } \\
(21-42 \%)\end{array}$} & \multicolumn{2}{|c|}{$\begin{array}{c}\text { III } \\
18-26 \\
\text { points } \\
(43-63 \%)\end{array}$} & \multicolumn{2}{|c|}{$\begin{array}{c}\text { IV } \\
27-34 \\
\text { points } \\
(64-82 \%)\end{array}$} & \multicolumn{2}{|c|}{$\begin{array}{c}\mathrm{V} \\
35-42 \\
\text { points } \\
(83-100 \%)\end{array}$} \\
\hline & category & $\mathrm{N}$ & $\mathrm{f}$ & $p(\%)$ & $\mathrm{f}$ & $p(\%)$ & $\mathrm{f}$ & $p(\%)$ & $\mathrm{f}$ & $p(\%)$ & $\mathrm{f}$ & $p(\%)$ \\
\hline total & - & 243 & 53 & 21.8 & 107 & 44 & 70 & 28.8 & 13 & 5.4 & 0 & 0 \\
\hline \multirow[t]{2}{*}{ gender } & male & 132 & 29 & 22 & 55 & 41.7 & 44 & 33.3 & 4 & 3 & 0 & 0 \\
\hline & female & 111 & 24 & 21.6 & 52 & 46.9 & 26 & 23.4 & 9 & 8.1 & 0 & 0 \\
\hline \multirow[t]{2}{*}{ age } & I grade & 121 & 45 & 37.2 & 60 & 49.6 & 16 & 13.2 & 0 & 0 & 0 & 0 \\
\hline & III grade & 122 & 8 & 6.6 & 47 & 38.5 & 54 & 44.3 & 13 & 10.6 & 0 & 0 \\
\hline \multirow[t]{3}{*}{ school } & $\mathrm{BJ}^{*}$ & 66 & 13 & 19.7 & 34 & 51.5 & 15 & 22.7 & 4 & 6.1 & 0 & 0 \\
\hline & $\mathrm{NV}^{*}$ & 93 & 25 & 26.9 & 41 & 44.1 & 25 & 26.9 & 2 & 2.1 & 0 & 0 \\
\hline & $\mathrm{ILR}^{\star}$ & 84 & 15 & 17.9 & 32 & 38.1 & 30 & 35.7 & 7 & 8.3 & 0 & 0 \\
\hline
\end{tabular}

${ }^{\star}$ Designations of the elementary schools participating in research

The majority of the students' scores belonged to the first three intervals, and the majority of students had scores within interval II. The proportion of students scoring $64 \%$ or more was minor.

\section{Differences between subpopulations (in test scores)}

Differences in the number of points scored according to gender were tested by the Mann-Whitney test. The obtained value $U=7274.5$ with $p=0.0924829$ was not statistically significant, indicating that there is no statistically significant difference among boys and girls in the test results. 
Differences in the number of points scored according to age were also tested by Mann-Whitney test. The obtained value $U=2827.5$ with $p=0.000$ was statistically significant, indicating that there is statistically significant difference among the first and third graders in the test results.

Differences according to the school were tested by Kruskal-Wallis test and the obtained value $H=4.987346$, with $p=0.0826>0.05$ showed that no statistically significant difference in test scores among students from different schools could be observed.

\section{Analysis of the first- and third-graders' answers}

The children's answers were classified according to subject contents (questions) and types of answers (spontaneous, synthetic, "I don't know" and scientific) by grades (first grade and third grade) (Figure 1 and 2).

Regarding the first question "What will happen with a glass full of water which has no cover if we leave it outdoors for a couple of days?", scientific and spontaneous answers were dominant (Figure 1). These two types of answers were equally represented among first-graders (spontaneous $-42.99 \%$, scientific $42.13 \%$ ), while third-graders more frequently provided scientific answers (spontaneous $-25.64 \%$, scientific 57.86\%). The most frequent incorrect (spontaneous) answers were that water will: "spoil”, “warm up", "remain the same", "spill”, "be old”, “ turn into liquid”, "get dirty", "someone will drink it", "dry out", “disappear".

It is interesting that the reverse situation - more scientific answers obtained from first-graders $(58.86 \%)$ than from third-graders $(40.49 \%)$ - was observed regarding the second question (Will water evaporate faster in a glass or in a plate?). It is evident that the concept of effect regarding the size of free surface to the rate of evaporation has not been adopted during preceding instruction, and that many of the third grade students were additionally confused. Incorrect answers that water will evaporate from glass faster were explained as follows: "the glass has larger free surface", " the glass stands and water will not spill", "because the glass is deeper", "it is warmer in the glass", "because it is narrower and wider" "because it has bigger volume", "because water cannot flow out from the glass", "nothing can evaporate on a flat surface".

What do people do to prevent roads and sidewalks become slippery in winter? was the third question, while in the fourth question the explanation was asked ("Why do people do that?"), aiming at adoption of the concept of (ice) melting phenomenon. It was noticeable that the majority of both groups knew that during winter sidewalks and roads are salted in order to melt the ice. However, none of the first-graders and only a few third-graders $(7.43 \%)$ could provide a scientific 
explanation of that phenomenon. Synthetic answers (73.55\% first-graders, and $72.73 \%$ third-graders) were predominant, suggesting that the ice melting concept was taught in class, but adequate and complete adoption of the scientific concept has not been established. Some of the wrong answers were: "they slide", "they sled", "they don't move", "they put on boots", "they walk slowly"

The fifth question was: "Why does it rain?" aiming at the adoption of concepts of evaporation and condensation (first grade) and water cycle in nature (third grade). Only a few first graders (8.24\%) and $15.68 \%$ third-graders understand this concept, while the majority of them do not understand it at all. Some spontaneous answers to the question 'why does it rain' were as follows: "the clouds cover the sun", "because it is a bad day", "so that water gets in the soil", " because it is cold", "because the cloud cries", "because God cries", "if it doesn't rain, everything would dry out" and "the rain falls so that we have more water".



Figure 1. Results of analysis of students' understanding water changes of state and water cycle (questions $1,2,3,4,5$ )

Marking the water level when water is poured from the one container to another narrower container was the assignment in the sixth task, intending to investigate the understanding of the concept of constant water volume and generally of conservation of measure. The ability to properly mark the water level in the 
second container demonstrated only $21.49 \%$ of the first-graders and $42.15 \%$ of the third-graders. Taking into account that the ability of understanding a concept of conservation of measure such as quantity, mass, length, surface and volume develops between the age of seven and twelve, the poor achievements can be assigned to the developmental limitations of participants.

In the seventh task, the students were asked to color the free surface of water in bottles placed vertically, horizontally and at a tilted angle and to determine the bottles with the biggest and the smallest free surface. Only 5.79\% of the first-graders and $26.45 \%$ of the third-graders correctly colored and compared the free surface sizes of water in the bottles. The large portion of synthetic answers $(42.98 \%$ of first-graders and $72.72 \%$ of third-graders) is a consequence of the fact that the majority of the students failed to determine in which bottle is the smallest free surface of water, and in which is the biggest, although they colored them properly. It is evident that children of this age are still not fully capable of adopting the concept of horizontality of free surface of liquid.

The answers to the eighth question Will the object with a hole sink or float if the same object without the hole floated? showed that more than a half of partic-

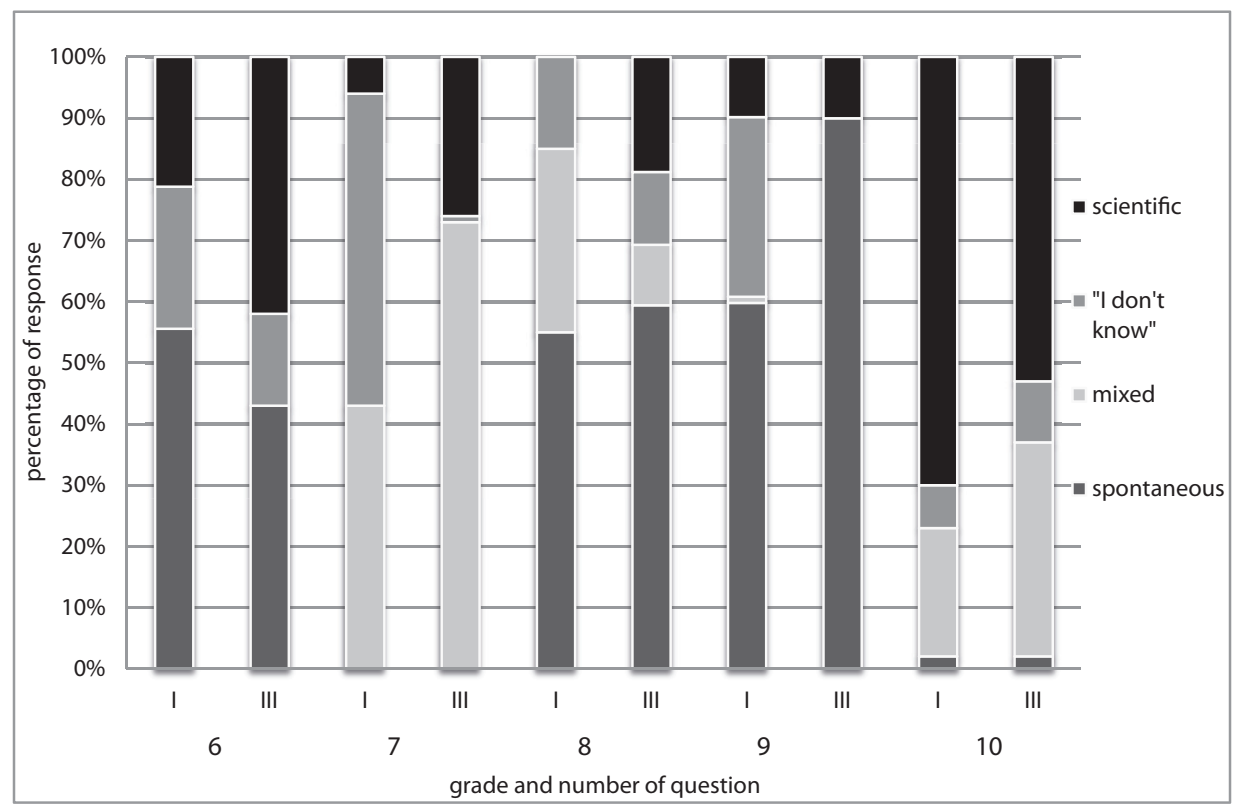

Figure 2. Results of the analysis of students' understanding basic properties of water (shape, volume, free surface), sinking and floating and solubility in water (questions 6, 7, $18,19,10)$ 
ipants believed that the object with a hole would sink, while only $18.19 \%$ of the third-graders correctly concluded that it would float, because the objects were made of the same material, i.e. of the same density. The most common explanations to the incorrect claim that the object with a hole would sink were: "it sinks with a hole because it leaks", "it sinks with a hole because it has not a flat surface", "it is heavier with a hole and therefore it sinks".

In the ninth task, the participants were asked to predict and explain whether the smaller ball would float or sink in water if the bigger ball made of the same material was floating. Only several first- and third-graders understood that the objects with the same densities (made of the same material), no matter the mass (size), will act in water in the same manner.

By means of the tenth question, the adoption of concept of solubility was examined. The children were asked to compare the solubility of sugar in warm and cold water. The majority of the students answered that sugar would dissolve in both glasses, but less students knew that the rate of dissolving increases with the increase of water temperature (70.25\% first-graders and $52.89 \%$ third-graders), while a significant number of children mistakenly believes that it is vice versa (21.49\% first-graders and $34.72 \%$ third-graders). It is interesting that older students showed worse results than younger ones, suggesting that adding other liquids in the third-grade curricula would compromise the already adopted concept of water as a solvent.

\section{Discussion}

The present investigation into the adoption of the concepts about the states of water and water cycle in nature reveals that almost half of the students are capable of recognizing the phenomena such as evaporation of water from an open glass, the dependency of the evaporation rate on the size of free surface, as well as melting ice in the presence of salt. However, only a minor number of children can explain processes such as the change of temperature melting point by adding salt or the mechanism of rain (Figure 1). The difference in the quality of adopted concepts between the first- and third-graders in favor of the older pupils is evident and expected, but it is worrying that even among them the percentage of adopted scientific concepts about the states of water and water cycle in nature does not go beyond $65 \%$, and in certain cases it is below $10 \%$.

The analysis of adoption of the second group of concepts (Figure 2), concerning the shape, volume and free surface of water, suggests that only about one fifth of 
the first-graders and two fifths of the third-graders understand the concept of conservation of volume, and the number of students understanding a horizontal position of free surface of water is even smaller (under $10 \%$ of first-graders and about one quarter of third-graders). Over $80 \%$ of the pupils cannot scientifically explain the floating and sinking phenomenon. Finally, the concept of solubility of substances in water is comprehensible to the majority of students and, unexpectedly, more clear to the first-graders than to the third-grade primary students.

The diversity of children's spontaneous and synthetic explanations of phenomena and processes, as well as their abundance, independent of the age, gender or school they attend, lead to the conclusion that teaching insufficiently contributes to the process of conceptual change from spontaneous to scientific concepts in learning about the properties of water.

\section{Conclusions}

The study confirmed the assumption that misconceptions about physical properties of water are widely present among elementary students and that teaching world around us and social and natural sciences did not sufficiently contribute to the development of scientific concepts about these phenomena. It has shown that children retain many naive ideas which should not be ignored, but rather used in the process of creating effective science teaching.

The misconceptions were more frequent among the first grade students as expected, but they were almost identical in terms of their nature (quality) in both subpopulations of participants and in concordance with similar studies by other authors (Kikas, 2005; Smolleck \& Hershberger, 2011). The frequency of synthetic and scientific answers was higher among the third-graders than the first-graders. This result was expected, bearing in mind that older children have more "experience", and they were also longer subjected to teaching.

It was confirmed that the test scores of the participants were not dependent on gender or school they attended, meaning that the results were equally poor. It can be attributed to the widespread teaching routine which develops only reproductive knowledge and does not contribute to the true understanding of scientific concepts.

The fact that many alternative (incorrect) concepts remained immune to the effects of the teaching process, implies the need for more frequent audit of students' knowledge, using conceptual tests or interviews, as well as the introduction of active learning in primary teaching (Obadović, Rančić, Cvjetićanin \& Segedinac, 
2013; Jablonsky, 2009), which would lead to the development of scientific concepts through the process of conceptual change (Pine, Messer \& John, 2001).

The established misconceptions in students' knowledge should be used as a useful tool for further teaching, because they are in fact a foundation for building true concepts and scientific knowledge.

\section{Acknowledgements}

This research is a part of a project number 179010, which was financially supported by a grant from the Ministry of Education, Science and Technological Development of the Republic of Serbia (2011-2019).

\section{References}

Allen, M. (2010). Misconception in Primary Science. New York: Open University Press. Bošnjak Stepanović, M., Gorjanac Ranitović, M. (2016). Implementation of the Project-based Learning - Opportunities and Difficulties. Proceedings "Education and the social challenges at the beginning of the $21^{\text {st }}$ century" (ed. D. Petrovic and M. Antolovic). Faculty of Education in Sombor, University of Novi Sad, p. 152-172.

Harlen, W. (2013). Assessment \& Inquiry-Based Science Education: Issues in Policy and Practice.

Global Network of Science Academies (IAP) Science Education Programme (SEP), Italy. Jablonsky, T. (2009). Cooperative learning as an innovative trend in education. The New Educational Review, 19 (3-4), 17-28.

Kikas, E. (2010). Children's thinking. Clouds, rain, and rainbow in children's explanations. Folklore, 44, 113-130.

Kubiatko, M. \& Prokop, P. (2009). Pupil's understanding of mammals: An investigation of the cognitive dimension of misconceptions. Orbisscholae, 3 (2), 97-112.

Obadović, D., Rančić, I., Cvjetićanin, S. \& Segedinac, M. (2013). The impact of implementation of simple experiments on the pupils positive attitude in learning science contest in primary school. The New Educational Review, 34 (4), 137-150.

Pallant, J. (2010). SPSS survival manual: A step by step guide to data analysis using the SPSS program. $4^{\text {th }}$ Edition, McGraw Hill, New York.

Pavlović - Babić, D. i Baucal, A. (2010). Nauči me da mislim, nauči me da učim. PISA 2009 u Srbiji: prvi rezultati (Teach me to think teach me to learn. PISA 2009 in Serbia: first results). Beograd: Institut za psihologiju Filozofskog fakulteta.

Petrović, V. (2006). Razvoj naučnih pojmova u nastavi poznavanja prirode (Development of scientific concepts in science teaching). Jagodina: Učiteljski fakultet u Jagodini, Univerzitet u Kragujevcu. 
Pine, K., Messer, D. \& St. John, K. (2001). Children's Misconceptions in Primary Science: A Survey of teachers' views. Research in Science \& Technological Education, 19 (1), 79-96. Smolleck, L. \& Hershberger, V. (2011). Playing with Science: An Investigation of Young Children's Science Conceptions and Misconceptions. Current Issues in Education, 14 (1), 1-32.

Taylor, A. \& Kowalski, P. (2004). Naïve Psychological science: The prevalence, strength, and sources of misconceptions. The Psychological Record, 54, 15-25.

Yin.Y., Tomita, M., Shavelson, R. (2008). Diagnosing and Dealing with Student Misconceptions: Floating and Sinking. Science Scope, April/May 2008, 34-39. 